\title{
Use of the Point Defect Model to interpret the iron oxidation kinetics under proton irradiation
}

\author{
S. Lapuerta, N. Moncoffre, H. Jaffrézic, N. Millard-Pinard,
}

Université Claude Bernard Lyon I (UCBL), Institut de Physique Nucléaire de Lyon (IPNL), Institut National de Physique Nucléaire et de Physique des Particules (IN2P3)/ Centre National de Recherche Scientifique (CNRS), 4 rue Enrico Fermi, 69622 Villeurbanne cedex, France.

N. Bérerd

UCBL, Institut Universitaire Technologique A and IPNL, IN2P3/CNRS, 94, boulevard du Niels Bohr, 69622 Villeurbanne cedex, France

C. Esnouf

Groupe d'Études de Métallurgie Physique et de Physique des Matériaux (GEMPPM), Institut National des Sciences Appliquées de Lyon(INSA), 20 Av. A. Einstein, 69621 Villeurbanne, France

D. Crusset

Agence Nationale pour la gestion de Déchets Radioactifs (ANDRA), Parc de la Croix Blanche 1-7 rue Jean Monnet, F-92298 Châtenay-Malabry Cedex, France (Received

This paper concerns the study of iron corrosion in wet air under $\mathrm{MeV}$ proton irradiation for different fluxes at room temperature and with a Relative Humidity $(\mathrm{RH})$ fixed to $45 \%$. Oxidised iron sample surfaces are characterised by ion beam analysis (Rutherford Backscattering Spectrometry (RBS) and Elastic Recoil Detection Analysis (ERDA)), for the elemental analysis. The structural and physicochemical characterisation is performed using 
the X-ray Photoelectron Spectroscopy (XPS) and Transmission Electron Microscopy (TEM) techniques. We have also measured the iron oxidation kinetics. Radiation enhanced diffusion and transport processes have been evidenced. The modelling of the experimental data shows that the apparent oxygen diffusion coefficient increases whereas the oxygen transport velocity decreases as function of flux. Finally, the Point Defect Model (PDM) has been used to determine the electric field value in the samples. Results have shown that the transport process can be attributed to the presence of an electrical potential gradient.

PACS numbers: 68.35.Fx, 61.80.-x, 68.37.Lp, 28.41.Kw 


\section{INTRODUCTION}

This work is performed in the frame of the research on high level nuclear wastes deep geological storage. At the moment in France, these wastes are vitrified in stainless steel containers and stored in surface disposals. It is foreseen that, during storage, they will be put in low-alloyed steel overpacks. In the first hundred years, the relative humidity should be close to $100 \%$. The air oxygen content will rapidly decrease as a function of time and water should penetrate in the storage site and reach the overpacks. In a very radioactive medium, water and air radiolysis will occur and likely accelerate the corrosion processes. From this industrial problem, we have defined a fundamental study on the effects of water and air radiolysis on iron corrosion, the radiolysis being induced by $\mathrm{MeV}$ proton irradiation.

In the literature, Lillard et al. ${ }^{1}$ have put in evidence the enhancement of steel corrosion in contact with proton irradiated water. Moreover, influence of dissolved species $\left(\mathrm{N}_{2}, \mathrm{O}_{2}\right)$ in water has been studied by Petrik et $a .^{2}$ in copper and by Burns et $a l .^{3}$ in steels by using $\gamma$ irradiation. They have in particular shown that the corrosion rate increases in presence of dissolved air in water.

Wet air radiolysis has been mainly studied under $\gamma$ irradiation. Wayne-Sieck et al. ${ }^{4}$ have shown that more than $80 \%$ of radiolytic charged species are $\mathrm{H}^{+}\left(\mathrm{H}_{2} \mathrm{O}\right)_{\mathrm{n}}$ clusters. Willis et $a l .{ }^{5}$ have determined the primary yields of the different radiolytic species. Kanda et al. ${ }^{6}$ have compared the formation velocities of non-radical species in dry and wet air. They have shown that $\mathrm{HNO}_{3}$ and $\mathrm{HNO}_{2}$ are only formed in humid air.

In addition, iron corrosion without irradiation has been widely studied. It is known that the corrosion layer is a complex mixture of oxide and hydroxide components ${ }^{7}$. Greadel et $a l^{8}$ and Baklouti et al. ${ }^{9}$ have shown that the air composition and in particular humidity, influence the 
corrosion rate of iron and its alloys. Corrosion really starts for a Relative Humidity (RH) of 60 $\%$ and is of major importance at $80 \%$.

In our study, we have chosen to focus on the effects of wet air radiolysis on iron corrosion. Iron is a reference material and radiolysis is induced by proton irradiation in order to accelerate very significantly the radiolytic processes compared to $\gamma$ irradiation. The aim of this paper is to study the influence of the proton beam flux on the iron corrosion rate. The air RH was fixed to $45 \%$ since it was shown in a previous paper ${ }^{10}$ that the corrosion is maximum at this $\mathrm{RH}$ in our experimental conditions. As well, it was demonstrated ${ }^{11}$ that both oxygen and water are required to favour the corrosion process.

The radiation enhanced oxygen diffusion in iron must be studied in a well characterised material. It is the reason why, oxygen and hydrogen distribution profiles have been first determined by using respectively Rutherford Backscattering Spectrometry (RBS) and Elastic Recoil Detection Analysis (ERDA). Moreover, X-ray Photoelectron Spectroscopy (XPS) and Transmission Electron Microscopy (TEM) complementary analyses have been also performed to characterise the corroded iron surface. The iron oxidation kinetics under irradiation has been then obtained. The electric field influence in the corroded layer has been deduced using the Point Defect Model (PDM) ${ }^{12-16}$.

\section{EXPERIMENTAL SET-UP}

\section{A. Iron irradiation}

Samples are $10 \mu \mathrm{m}$ thick pure iron discs $(99.985 \%)$. With such a thin thickness, they cannot be polished and are irradiated as provided by Goodfellow. The surface is thus slightly oxidised. The $3 \mathrm{MeV}$ proton irradiations are performed on the external beam line of the $4 \mathrm{MV}$ 
Van de Graaff accelerator of the Nuclear Physics Institute of Lyon. The experimental set-up presented in Fig. 1 has been previously described ${ }^{11}$. The beam is extracted from the vacuum by a $5 \mu \mathrm{m}$ thick Havar window and penetrates in the irradiation cell through the iron foil. In between the Havar and the iron foils, protons go through $8 \mathrm{~mm}$ of wet air (air gap). At that stage, the proton energy is $2.75 \mathrm{MeV}$. The iron electronic stopping power calculated by $\mathrm{SRIM}^{17}$ is then $55.9 \mathrm{keV} \mu \mathrm{m}^{-1}$ and largely prevails compared to the nuclear stopping power. Protons finally stop into water after a $100 \mu \mathrm{m}$ range. A sweeping system allows to irradiate homogeneously a $5 \times 5 \mathrm{~mm}^{2}$ surface. The beam current measurement is performed with a beam chopper placed in front of the Havar window.

The RH is fixed to $45 \%$ using the following system ${ }^{11}$ : the dry gas $\left(\mathrm{O}_{2}+\mathrm{N}_{2}\right)$ supply is provided from a bottle which flow is regulated with a manometer. The dry gas is saturated with water through a bubbling system and is adjusted to the proper $\mathrm{RH}$ value by using an alumina trap. This value is measured using a Hygropalm humidity controller.

To study the proton irradiation influence on iron corrosion, irradiations were realised using 4 different fluxes: $1.25 \times 10^{11}, 2.5 \times 10^{11}, 5 \times 10^{11}$ and $7.5 \times 10^{11}$ protons $\mathrm{s}^{-1} \mathrm{~cm}^{-2}$. In order to obtain the oxidation kinetics, the irradiation time was varied from 5 to 45 minutes for each flux.

\section{B. Sample analysis}

After each irradiation, the sample surfaces in contact with the gaseous medium were analysed using RBS (with 1.7 to $3 \mathrm{MeV}$ alpha particles) and ERDA (with $1.7 \mathrm{MeV}$ alpha particles) in order to determine oxygen and hydrogen distribution profiles. To characterize the near surface chemical state of the corroded layer, XPS experiments were also performed. Samples were previously cleaned using hexane, acetone and ethanol ultrasound baths to dissolve the superficial layer essentially polluted by carbon. In order to avoid iron oxide 
reduction, in-situ surface ion beam etching was never performed. Hence, only the very near surface was analysed. High resolution analyses were realised on the iron $2 p_{3 / 2}$ and oxygen $1 \mathrm{~s}$ signals.

Oxide crystallographic phases were characterized using TEM, and more precisely the electronic diffraction method, at the CLYME (Centre LYonnais de Microscopie Electronique) of Lyon. Measurements were performed using a JEOL $200 \mathrm{CX}$ transmission microscope which provides $200 \mathrm{keV}$ electrons and has a camera length equal to $80 \mathrm{~cm}$. For this analysis, the surface iron oxide was mechanically removed from the sample surface and the so recovered powder was deposited on a carbon film covering a classic copper grid.

\section{CORRODED LAYER CHARACTERISATION}

\section{A. Elementary analysis}

Fig. 2 shows ERDA (a) and RBS (b) experimental spectra obtained for non-irradiated samples (called initial samples in the following) and corroded ones irradiated during 45 minutes, for $2.5 \times 10^{11}$ and $7.5 \times 10^{11}$ protons $\mathrm{s}^{-1} \mathrm{~cm}^{-2}$ fluxes. From these spectra and using the SIMNRA simulation code ${ }^{18}$, oxygen and hydrogen concentration profiles were deduced.

Results are plotted in Fig. 3 for the initial and 45 minute irradiated samples. Concerning the initial sample, Fig. 3a shows that hydrogen is present only at the very near surface which is typical of an atmospheric contamination. For the other samples, hydrogen is present deeper. Nevertheless, this analysis is limited to the first $150 \mathrm{~nm}$, and this point prevents the determination of the total hydrogen quantity present in the sample. Fig. $3 \mathrm{~b}$ displays that the oxygen surface concentration increases as a function of flux up to $5 \times 10^{11}$ protons $\mathrm{s}^{-1} \mathrm{~cm}^{-2}$. However, the surface concentration remains constant for proton fluxes higher 
than $5 \times 10^{11}$ protons $\mathrm{s}^{-1} \mathrm{~cm}^{-2}$. The oxygen concentration profiles show that the formed oxides are not stoichiometric on the whole analysed depth. Indeed, the oxygen concentration is maximum at the surface and decreases with depth.

\section{B. Structural and physicochemical analysis}

To determine the chemical composition of the formed phases and their crystallographic structure, we have performed XPS and TEM analyses.

The XPS analyses were realised on the corroded samples irradiated during 30 minutes with protons fluxes varying from $1.25 \times 10^{11}$ to $5 \times 10^{11} \mathrm{p} \mathrm{s}^{-1} \mathrm{~cm}^{-2}$. Spectra are plotted in Fig. 4. These results allow to identify the different oxidation states of iron ${ }^{19}$ and to determine the oxide and hydroxide ratio at the surface ${ }^{20,21}$. A quantitative analysis is made on the basis of the peak decomposition performed on each spectrum (an example is presented in Fig. 4c). The characteristics of the different components used in the decomposition procedure of the iron $2 \mathrm{p}_{3 / 2}$ peak and oxygen $1 \mathrm{~s}$ peak are reported respectively in Table I and Table II. In Table II, the presence of $\mathrm{C}-\mathrm{O}$ components is due to a classical contamination at the surface. Concerning the iron $2 p_{3 / 2}$ signal (Table I and Fig. $\left.4 a\right)$, the initial sample is a mixture of $\mathrm{Fe}^{0}(8 \%), \mathrm{Fe}^{2+}(20$ \%) and $\mathrm{Fe}^{3+}(72 \%) . \mathrm{Fe}^{2+}$ and $\mathrm{Fe}^{3+}$ proportions are close to those of $\mathrm{Fe}_{3} \mathrm{O}_{4}$. We can note that, for all the irradiated samples and for each flux, only the $\mathrm{Fe}^{3+}$ signal is observed. Concerning the oxygen $1 \mathrm{~s}$ signal, Table II and Fig. $4 \mathrm{~b}$ displays that the initial sample contains the same quantity of oxide and hydroxide phases whereas, for the irradiated ones, the iron hydroxide is preferentially formed. These results show that the corroded layer is a mixture of hydroxide and oxide phases, and that the proton irradiation enhances the hydroxide phase formation. Moreover, we can see the presence of an adsorbed water layer at the surface of each sample. 
TEM analyses were performed on a 90 minute sample irradiated with a flux equal to $1.25 \times 10^{11}$ protons $\mathrm{s}^{-1} \mathrm{~cm}^{-2}$. In Fig. 5a, rectangular crystals bounded by amorphous zones as confirmed by electron diffraction pattern are observed. Their mean size is close to $50 \mathrm{~nm}$. Electronic diffraction analysis was realised on a crystal at different tilt angles using a tilt rotation specimen holder. A stereographic projection was built from diffraction patterns (Fig. 5b) performed on one crystal. It matches precisely with a cubic structure. Table III shows the diffraction pattern indexation. From this table, we can deduce the crystal lattice parameter which is equal to $0.572 \mathrm{~nm}$. Moreover for each reticular plane, we note that the Miller indexes have the same parity, which is characteristic of a face centered cubic phase (FCC). The most known FCC iron oxide structure is magnetite but its lattice parameter is equal to $0.8375 \mathrm{~nm}^{22}$. The irradiation enhanced structure does not seem to correspond to any iron oxide or hydroxide phases listed in JCPDS data ${ }^{22}$. For comparison, let us mention the work of M. F. Toney et $a l .{ }^{23}$ and Davenport et $a l^{24}$ who have also synthesised passive oxide films on iron. They have analysed the formed phases very finely and shown that they were either amorphous or of spinel type but neither $\gamma-\mathrm{Fe}_{2} \mathrm{O}_{3}$ or $\mathrm{Fe}_{3} \mathrm{O}_{4}$ nor any combination of these phases agree with experimental data. The authors propose an atomic structure based on a fec lattice having a lattice parameter close to $0.84 \mathrm{~nm}$ but showing an atomic arrangement different of previously mentioned phases. In our case, the crystalline symmetry is analogue but the atomic order seems to be different and higher in the sense where the periodic arrangement is shorter. All these results seem to show that irradiation produces non equilibrium phases.

\section{IRON OXIDATION KINETICS STUDY}


We have determined the iron oxidation kinetics under $2.75 \mathrm{MeV}$ proton irradiation, at $25^{\circ} \mathrm{C}$. From the experimental results presented in Fig. $3 \mathrm{~b}$, we have evaluated the apparent oxygen diffusion coefficient.

\section{A. Apparent oxygen diffusion coefficient determination}

Fig. 6 represents the oxygen gain $\log (M(t))$ as a function of $\log (t)$, $t$ being the irradiation time for each flux. The obtained data fit with straight lines which slopes are close to 0.7 . This value is different from 0.5 which is expected for a pure diffusion process. Hence, the involved diffusion phenomena are likely enhanced by a transport mechanism due to a driving force whose origin will be discussed in section B.

These processes, which occur into the oxide layer, can be modelled by the transport equations $^{25}$ :

$$
\begin{aligned}
& J(x, t)=-D \frac{\partial c(x, t)}{\partial x}+v c(x, t) \\
& \frac{\partial c(x, t)}{\partial t}=-\frac{\partial J(x, t)}{\partial x}=D \frac{\partial^{2} c(x, t)}{\partial x^{2}}-v \frac{\partial c(x, t)}{\partial x}
\end{aligned}
$$

where $J(x, t)$ corresponds to the flux of incoming oxygen ions, $c(x, t)$ is the oxygen concentration, $\mathrm{x}$ is the depth, $\mathrm{t}$ is the time, $\mathrm{D}$ is the apparent oxygen diffusion coefficient, and $\mathrm{v}$ is the oxygen transport velocity in the solid. The second term of each equation is called either transport or migration term.

The solution depends on initial and boundary conditions. In the solid iron target, they are the following:

$$
\begin{aligned}
& c(x, 0)=0 \\
& c(\infty, t)=0
\end{aligned}
$$


Using these conditions, the equation (2) is numerically solved. D and v values are obtained by fitting the theoretical concentration profiles with the experimental ones. Fig. 7 illustrates the result obtained for experimental conditions corresponding to a 15 minute irradiation time and a $5 \times 10^{11}$ protons $\mathrm{s}^{-1} \mathrm{~cm}^{-2}$ flux. The fitting procedure was applied to all irradiation times and each flux. The average $\mathrm{D}$ and $\mathrm{v}$ values are reported in Table IV.

Results show that when the proton flux increases, the apparent diffusion coefficient increases whereas the transport velocity decreases until being equal to 0 for the $7.5 \times 10^{11}$ protons $\mathrm{s}^{-1} \mathrm{~cm}^{-2}$ flux. Considering the general equations (1) and (2), the fact that the D coefficient increases and that the $\mathrm{v}$ coefficient decreases could explain that the oxygen profiles are the same at $5 \times 10^{11}$ and $7.5 \times 10^{11}$ protons $\mathrm{s}^{-1} \mathrm{~cm}^{-2}$ fluxes (Fig. $3 \mathrm{~b}$ and Fig. 6).

\section{B. Determination of the electric field induced by irradiation using the Point Defect Model}

As a generality, the origin of the transport process can be attributed to different gradients $^{25}$ : electrical, chemical potentials, stress or temperature. As the proton energetic loss $\Delta \mathrm{E}$ in iron is weak $(\Delta \mathrm{E}=750 \mathrm{keV})$, the associated temperature variation is low. Since the 2.75 $\mathrm{MeV}$ proton stopping power in iron is mainly electronic, irradiation induces a slight number of defects, creating little strain. Finally, the chemical potential gradient does not depend on the proton flux. Consequently, chemical potential, temperature and stress gradients are probably not at the origin of transport in our experimental conditions.

In presence of the beam, the only gradient which can evolve as a function of the flux is the electrical potential gradient. Let us consider Fig. 8 which schematises the humid 
air/metal/oxide interfaces of the samples. Without irradiation (Fig. 8a), the free electrons coming from the iron metal can tunnel the oxide layer and reduce the dissolved oxygen in the adsorbed water layer. The surface polarity is negative, whereas the oxide/metal interface polarity is positive ${ }^{12}$, which creates an electrical field $\vec{E}_{o x / M}$ directed from the metal to the surface.

Under irradiation, the migration of the electrical charges carried on by protons, induces an electrical field $\overrightarrow{\mathrm{E}}_{\text {irr }}$ in the sample (Fig. 8b) which has the same direction as the beam. The resulting electrical field $\overrightarrow{\mathrm{E}}$ is the sum of both contributions:

$$
\overrightarrow{\mathrm{E}}=\overrightarrow{\mathrm{E}}_{\mathrm{irr}}+\overrightarrow{\mathrm{E}}_{\mathrm{ox} / \mathrm{M}}
$$

Consequently, the driving force acting on the oxygen ions is a Coulomb force. Considering the approximation where the mechanical energy of the Coulomb force is small with regard to RT, the resulting velocity ${ }^{25}$ can be written by:

$$
\mathrm{v}=\frac{\mathrm{nFDE}}{\mathrm{RT}}
$$

where $\mathrm{n}$ is the charge number of the positive ions diffusing through the film, $\mathrm{R}$ is the gas constant, $\mathrm{T}$ the temperature and $\mathrm{F}$ is the Faraday constant.

To evaluate E, we have used the Point Defect Model (PDM) ${ }^{13,14,15,16}$. The PDM has been developed for electrochemical experiments to interpret anodic oxide growths. This model considers that the system \{solution + oxidised metal\} is made of three layers: the solution, the barrier layer (the oxide) and the metal. It supposes that electrons from the metal tunnel through the oxide layer to form an oxygen anion at the solution/oxide interface. Moreover, in the PDM, the generation and annihilation of point defects maintain the electric field in the oxide constant whatever the potential drop across the oxide and the oxide thickness.

In a previous study ${ }^{11}$, we have shown that the iron corrosion in humid air and under irradiation corresponds to an anodic oxide growth. Indeed, we have observed by XPS (Table 
II) the presence of an adsorbed water layer at the sample surface. Consequently, we can assume that our sample is made of the three layer system described previously: the solution (adsorbed water layer), the barrier layer (oxide layer) and the metal. Moreover, we can consider that irradiation induces a potential. Finally, our system is electrically equivalent to the model described by D. D. Macdonald ${ }^{13}$, which allows to apply the PDM to interpret our experiments. However, PDM is generally used for thin oxide films (a few nanometers) but Mukhambetov and Chalaya ${ }^{12}$ have used it the PDM to study iron oxidation at different temperatures $(650-750 \mathrm{~K})$ with oxide thicknesses within the same range than ours. In this paper, thicknesses are about a few hundreds nanometers. Moreover, when the $\mathrm{MeV}$ proton beam flux is varied, the point defect concentration varies as well which implies that for each experiment, the electric field strength value changes.

In that model, E is expressed using the equation (8) from Kim et al. ${ }^{16}$ :

$$
E=-\frac{R T}{\alpha n F} \frac{d}{d M(t)}\left(\ln \frac{d M(t)}{d t}\right)
$$

where $\alpha$ is the transfer coefficient (ranging from 0 to 1 ), $\mathrm{n}$ is the charge number of the positive ions, $\mathrm{M}(\mathrm{t})$ is the oxide thickness and $\mathrm{t}$ the irradiation time.

In Fig. 9, we have plotted $\ln \left(\frac{\mathrm{dM}(\mathrm{t})}{\mathrm{dt}}\right)$ as a function of $\mathrm{M}(\mathrm{t})$ using the results presented in Fig. 6. It displays straight lines for the various fluxes which comforts the use of the PDM as demonstrated by Kim et al. ${ }^{16}$. We can determine that the slopes of those lines are equal to $-\frac{\mathrm{E} \alpha \mathrm{nF}}{\mathrm{RT}} \cdot \mathrm{n}$ is taken equal to 3 corresponding to $\mathrm{Fe}^{3+}$ and, like Kim et al., we assume that $\alpha$ is equal to 0.5 . Moreover, at room temperature, $\mathrm{RT} / \mathrm{F}$ is equal to $0.023 \mathrm{~V}$. Considering these values, E has been calculated for each proton flux. The results are reported in Table V which shows that E decreases as a function of the flux. Like D. D. Macdonald ${ }^{13}$ who has shown the 
photoquenching of the electric field strength on nickel, we can suggest that proton irradiation tends to quench E.

To resume, we have observed that $\mathrm{v}$ decreases as a function of the proton flux to reach 0 for the highest flux (Table IV). Thus, for this value and in the transport equations (1) and (2), the migration term does not act anymore and only the first term remains. This result is clearly shown in Fig. $3 b$ where a kind of saturation as a function of flux occurs in the surface oxygen concentration.

\section{CONCLUSION}

In this paper, we have studied the influence of proton flux on the iron oxidation under 2.75 MeV proton irradiation in wet air ( $\mathrm{RH}$ fixed to $45 \%$ ). We have shown that the Point Defect Model, generally used for the modelling of oxide layer growths by electrochemical methods, can be applied to the study of iron oxidation kinetics under proton irradiation. The origin of the transport process is attributed to an electric field which is calculated using the PDM, and which tends to zero with the increasing proton beam flux.

\section{Acknowledgements}

The authors would like to thank Noëlle Chevarier for her very helpful contribution in the frame of fruitful discussions. 
${ }^{1}$ R.S. Lillard, D.L. Pile, D.P. Butt, J. Nucl. Mater. 278, 277 (2000)

${ }^{2}$ N.G. Petrik, M.N. Petrov and V.G. Fomin, High Energy Chem. 31, n5, 308 (1997)

${ }^{3}$ W.G. Burns, W.R. Marsh and W.S. Walters, Rad. Phys. Chem. 21, n³, 259 (1983)

${ }^{4}$ L. Wayne-Sieck, T. J. Buckley, J. T. Herron and D. S. Green, Plasma chemistry and plasma processing, 21, $\mathrm{n}^{\circ} 3,441$ (2001)

${ }^{5}$ Willis and Boyd, J. Rad. Phys. Chem. 8, 71 (1976)

${ }^{6}$ Y.Kanda, T.Momose and M.Taira, Rad. Phys. Chem. 48, 49 (1996)

${ }^{7}$ S. Hoerle, F. Mazaudier, Ph.Dillmann, G.Santarini, Corrosion Science, 46(6), 1431 (2004)

${ }^{8}$ T.E.Graedel, R.P.Frankenthal, J. Electrochem. Soc., 137, 2395 (1990)

${ }^{9}$ M. Baklouti, N. Midoux, F. Mazaudier, D. Feron, J. Hazardous Mater. B85, 273 (2001)

${ }^{10}$ S. Lapuerta, $\mathrm{PhD}$ thesis, Lyon University, France, (2005)

${ }^{11}$ S. Lapuerta, N. Moncoffre, N. Bérerd, H. Jaffrézic, N. Millard-Pinard, D. Crusset, Nucl. Instr. and Meth. in Phys. Res. B, 249, 470 (2006).

${ }^{12}$ D.G. Mukhambetov and O.V. Chalaya, J. Vac. Sci. Technol. A20(3), 839 (2002)

${ }^{13}$ D.D. Macdonald, J. Electrochem. Soc., 139(12), 3434 (1992)

${ }^{14}$ C.Y. Chao, L.F. Lin, D.D. Macdonald, J. Electrochem. Soc. 128, 1187 (1981)

${ }^{15}$ L. Zhang, D.D. Macdonald, E. Sikora, J. Sikora, J. Electrochem. Soc. 145, 898 (1998)

${ }^{16}$ D.H. Kim, S.S. Kim, H.H. Lee, H.W. Jang, J.W. Kim, M. Tang, K.S. Liang, S.K. Sinha, and D.Y. Noh, J. Phys. Chem. B 108, 20213 (2004)

17 J.F.Ziegler, J.P.Biersack, « The Stopping Range of Ions in Matter », version 2000.40, (1998)

18 M. Mayer, SIMNRA User's Guide, Report IPP 9/113, Max-Planck-Institut für Plasmaphysik, Garching, Germany, (1997)

${ }^{19}$ T-C Lin, G. Seshadri, J. A. Kelber, Appl. Surf. Science 119, 83 (1997)

${ }^{20}$ I.D. Welsh and P.M.A. Sherwood, Phys. Rev. B 40, N9, 6386 (1989) 
${ }^{21}$ S. Suzuki, K. Yanagihara and K. Hirokawa, Surface and Interface Analysis, 30, 372 (2000)

22 JCPDS-International Centre for Diffraction Data, Edition (2001)

${ }^{23}$ M. F. Toney, A. J. Davenport, L. J. Oblonsky, M. P. Ryan and C. M. Vitus, Phys. Rev.

Letters 79, 4282 (1997)

${ }^{24}$ A. J. Davenport, L. J. Oblonsky, M. P. Ryan and M. F. Toneyd, J. Electrochem. Soc., 147, 2162 (2000)

25 J.Philibert, Atom movements, diffusion and mass transports in solids, Edited by EDP sciences (1991) 
Table captions

Table I: Relative percentages of the iron components identified by XPS from the iron $2 p_{3 / 2}$ signal as function of the irradiation conditions

\begin{tabular}{cccc}
\hline & $\mathrm{Fe}^{0}$ & $\mathrm{Fe}^{2+}$ & $\mathrm{Fe}^{3+}$ \\
\hline Decomposition parameters & $\mathrm{E}=707 \mathrm{eV}$ & $\mathrm{E}=709.6 \mathrm{eV}$ & $\mathrm{E}=711.2 \mathrm{eV}$ \\
& $\mathrm{FWHM}=1.8 \mathrm{eV}$ & $\mathrm{FWHM}=2.5 \mathrm{eV}$ & $\mathrm{FWHM}=3.3 \mathrm{eV}$ \\
\hline Initial sample & $8 \%$ & $20 \%$ & $72 \%$ \\
\hline $1.25 \times 10^{11}$ protons s$^{-1} \mathrm{~cm}^{-2}$ & $2 \%$ & - & $98 \%$ \\
\hline $2.5 \times 10^{11}$ protons s$^{-1} \mathrm{~cm}^{-2}$ & - & - & $100 \%$ \\
\hline $5 \times 10^{11}$ protons s$^{-1} \mathrm{~cm}^{-2}$ & - & - & $100 \%$ \\
\hline \hline
\end{tabular}


Table II: Relative percentages of the compounds identified by XPS from the oxygen 1s signal as function of the irradiation conditions

\begin{tabular}{|c|c|c|c|c|}
\hline & $\mathrm{FeO}, \mathrm{Fe}_{2} \mathrm{O}_{3}$ & $\mathrm{FeOO}^{*} \mathrm{H}$ & $\mathrm{C}-\mathrm{O}$ & Adsorbed water \\
\hline Decomposition & $\mathrm{E}=530.2 \mathrm{eV}$ & $\mathrm{E}=531.6 \mathrm{eV}$ & $\mathrm{E}=532.4 \mathrm{eV}$ & $\mathrm{E}=533.4 \mathrm{eV}$ \\
\hline parameters & $\mathrm{FWHM}=1.5 \mathrm{eV}$ & $\mathrm{FWHM}=1.5 \mathrm{eV}$ & $\mathrm{FWHM}=1.5 \mathrm{eV}$ & $\mathrm{FWHM}=1.5 \mathrm{eV}$ \\
\hline Initial sample & $41 \%$ & $38 \%$ & $15 \%$ & $6 \%$ \\
\hline $\begin{array}{l}1.25 \times 10^{11} \\
\text { protons } \mathrm{s}^{-1} \mathrm{~cm}^{-2}\end{array}$ & $34 \%$ & $37 \%$ & $22 \%$ & $7 \%$ \\
\hline $\begin{array}{l}2.5 \times 10^{11} \\
\text { protons } \mathrm{s}^{-1} \mathrm{~cm}^{-2}\end{array}$ & $37 \%$ & $41 \%$ & $17 \%$ & $5 \%$ \\
\hline $\begin{array}{c}5 \times 10^{11} \\
\text { protons s }{ }^{-1} \mathrm{~cm}^{-2}\end{array}$ & $29 \%$ & $49 \%$ & $17 \%$ & $5 \%$ \\
\hline
\end{tabular}


Table III: Inter-reticular distances $\mathrm{d}$ and Miller indexes $\{\mathrm{hkl}\}$ corresponding to the Fig. $5 \mathrm{~b}$ indexation.

\begin{tabular}{ccccc}
\hline \hline $\mathrm{d}(\mathrm{nm})$ & 0.330 & 0.286 & 0.305 & 0.128 \\
\hline Miller indexes & $\{111\}$ & $\{002\}$ & $\{220\}$ & $\{420\}$ \\
$\{\mathrm{hkl}\}$ & & & \\
\hline \hline
\end{tabular}


Table IV: Apparent diffusion coefficients D and velocities $\mathrm{v}$ obtained from the transport equation (1) for different fluxes

\begin{tabular}{ccccc}
\hline \hline Flux & & & & \\
$\left(10^{11}\right.$ protons s $\left.^{-1} \mathrm{~cm}^{-2}\right)$ & 1.25 & 2.5 & 5 & \\
& & & & \\
\hline $\mathrm{D}\left(\mathrm{cm}^{2} \mathrm{~s}^{-1}\right)$ & $(2.9 \pm 0.6) \times 10^{-13}$ & $(2.4 \pm 0.5) \times 10^{-13}$ & $(5.7 \pm 1.1) \times 10^{-13}$ & $(1.0 \pm 0.2) \times 10^{-12}$ \\
\hline $\mathrm{v}\left(\mathrm{cm} \mathrm{s}^{-1}\right)$ & $(3.4 \pm 0.7) \times 10^{-9}$ & $(3.0 \pm 0.6) \times 10^{-9}$ & $(5 \pm 1) \times 10^{-10}$ & 0 \\
\hline \hline
\end{tabular}


Table V: Electric field values deduced from the Point Defect Model as function of the irradiation conditions

\begin{tabular}{ccccc}
\hline \hline $\begin{array}{c}\text { Flux } \\
\left(10^{11} \text { protons s}^{-1} \mathrm{~cm}^{-2}\right)\end{array}$ & 1.25 & 2.5 & 5 & 7.5 \\
\hline $\mathrm{E}\left(\mathrm{V} \mathrm{cm}^{-1}\right)$ & 160 & 168 & 84 & 17 \\
\hline \hline
\end{tabular}


Figure captions

Fig. 1: Schematic representation of the irradiation set up

Fig. 2: ERDA (a) and RBS (b) experimental spectra

Fig. 3: Hydrogen profiles (a) deduced from ERDA measurements and oxygen profiles (b) deduced from RBS measurements for the initial sample and for the irradiated samples after 45 minute exposures at beam fluxes of $1.25 \times 10^{11}, 2.5 \times 10^{11}, 5 \times 10^{11}$ and $7.5 \times 10^{11}$ protons s $\mathrm{cm}^{-2}$. The depth in nanometers is calculated assuming $\rho=7.86 \mathrm{~g} \mathrm{~cm}^{-3}$.

Fig. 4: XPS spectra for the initial sample and for the irradiated ones concerning the iron $2 \mathrm{p}_{3 / 2}$ signal (a) and the oxygen 1s signal (b). Oxygen 1s peak decomposition for a 30 minute irradiated sample with a flux equal to $5 \times 10^{11}$ protons $\mathrm{s}^{-1} \mathrm{~cm}^{-2}(\mathrm{c})$

Fig. 5: TEM micrograph (a) and electron diffraction pattern (b) of a 90 minute sample irradiated with a flux equal to $1.25 \times 10^{11}$ protons $\mathrm{s}^{-1} \mathrm{~cm}^{-2}$. The diffraction pattern is obtained according a [001] zone axis.

Fig. 6: Iron oxidation kinetics under proton irradiation at $25^{\circ} \mathrm{C}$ for different fluxes. Experimental results are shown by dots. The full lines suppose a linear fit regression

Fig. 7: Oxygen profiles for a 15 minute irradiated sample with a $5 \times 10^{11}$ protons s $\mathrm{s}^{-1} \mathrm{~cm}^{-2}$ flux. Comparison between the experimental data (dots) and result of the fit (full lines)

Fig. 8: Schematic representation of the electrical fields at the sample surface without irradiation (a) and under proton irradiation (b)

Fig 9: Use of the Point Defect Model. The slopes. -EonF/RT of the straight lines allow to determine the electric field $\mathrm{E}$ 


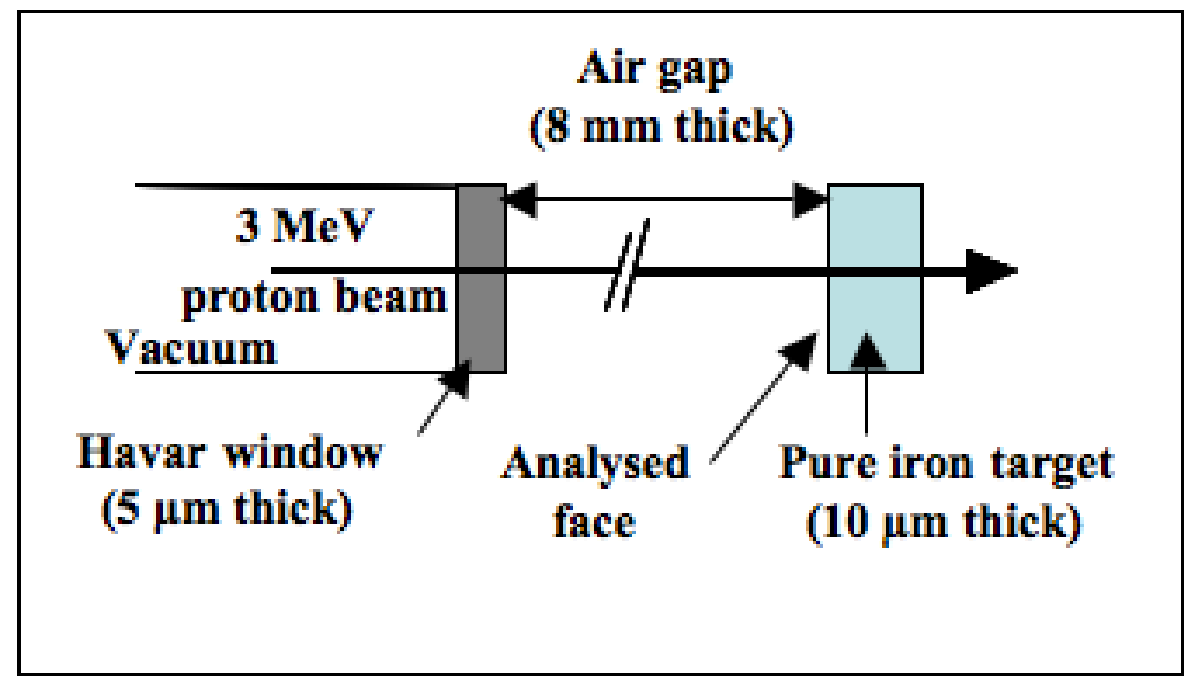



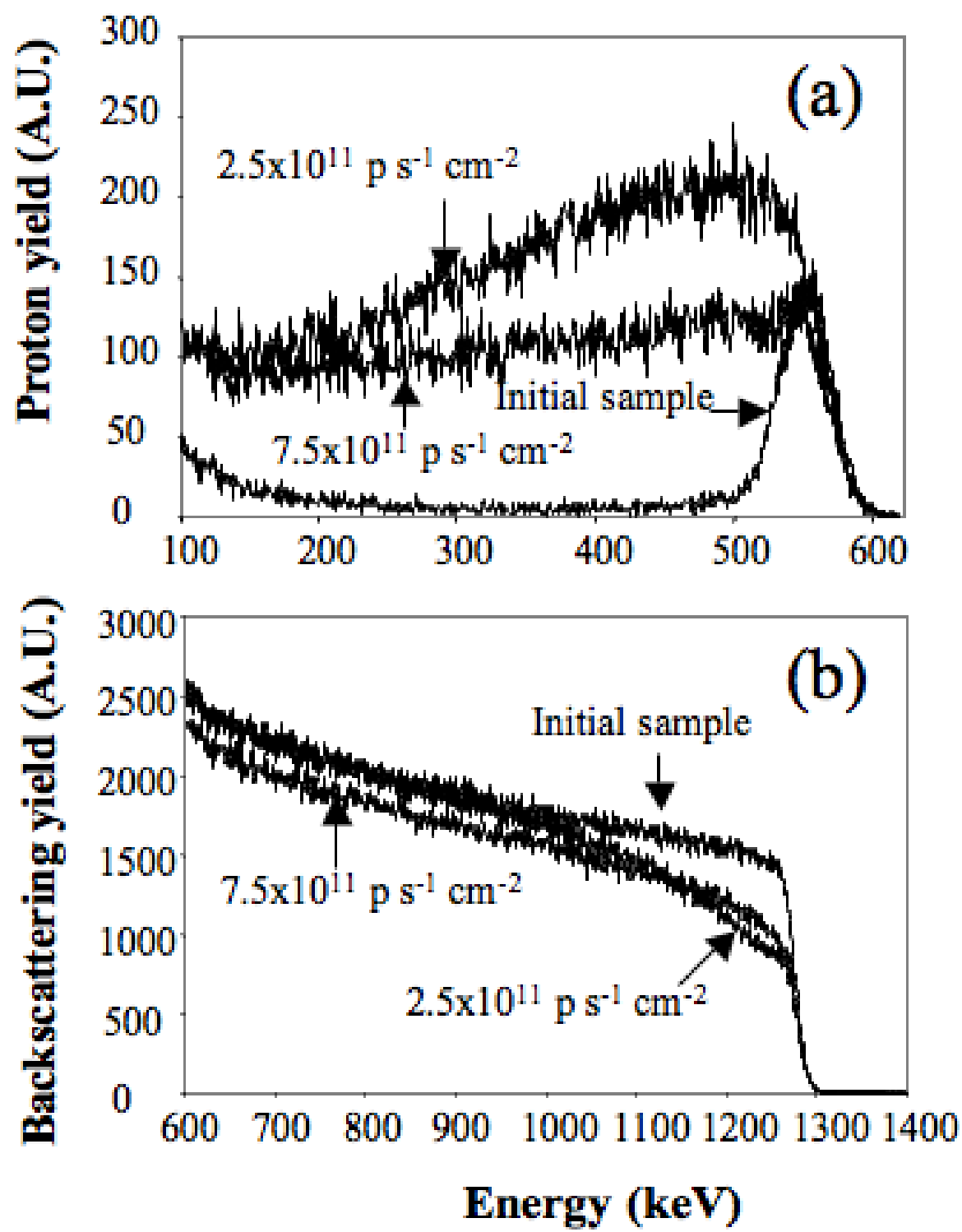
Depth (nm)

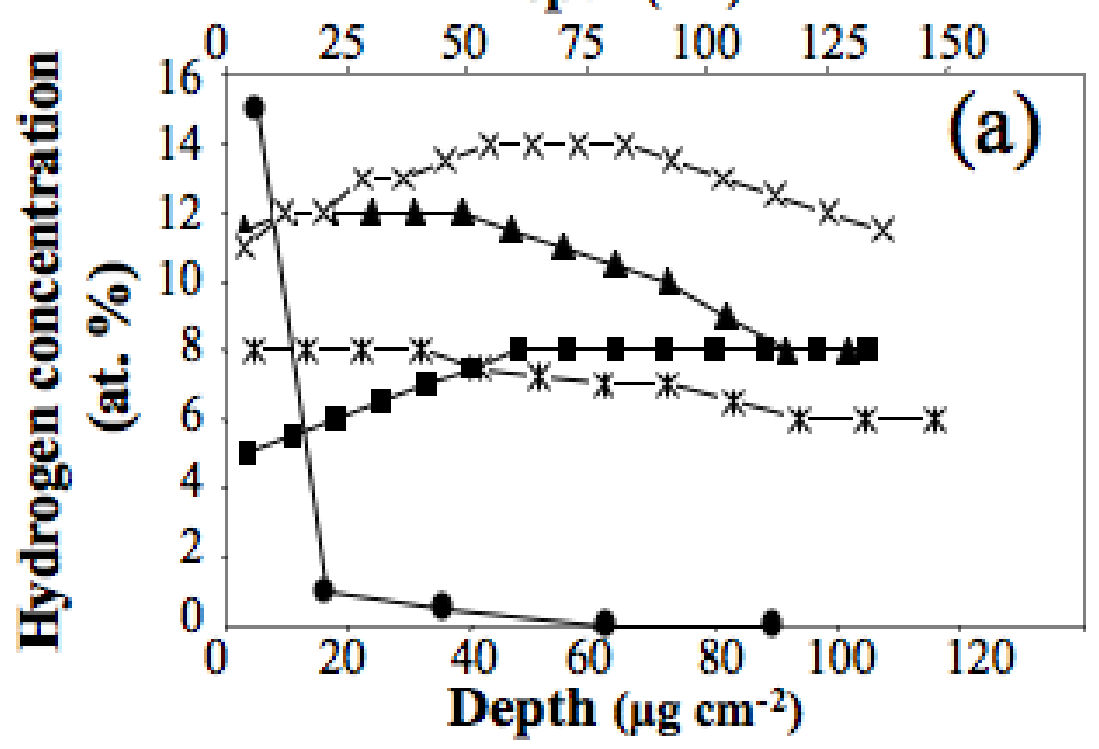

Depth (nm)

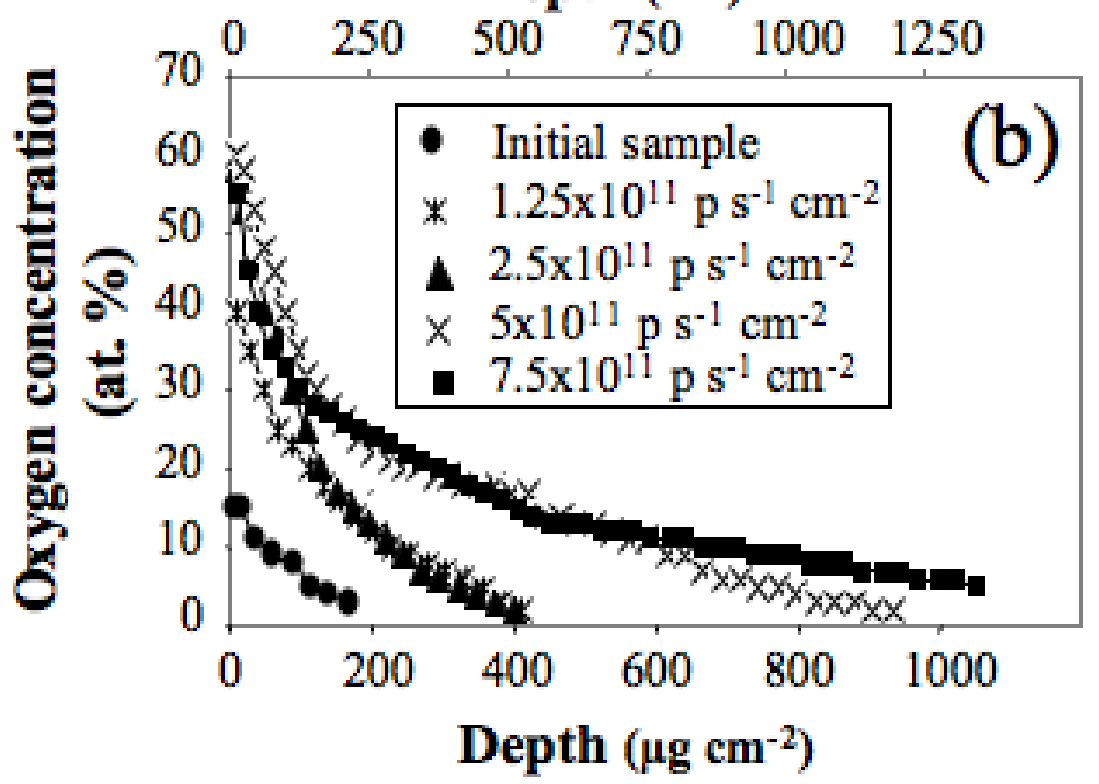




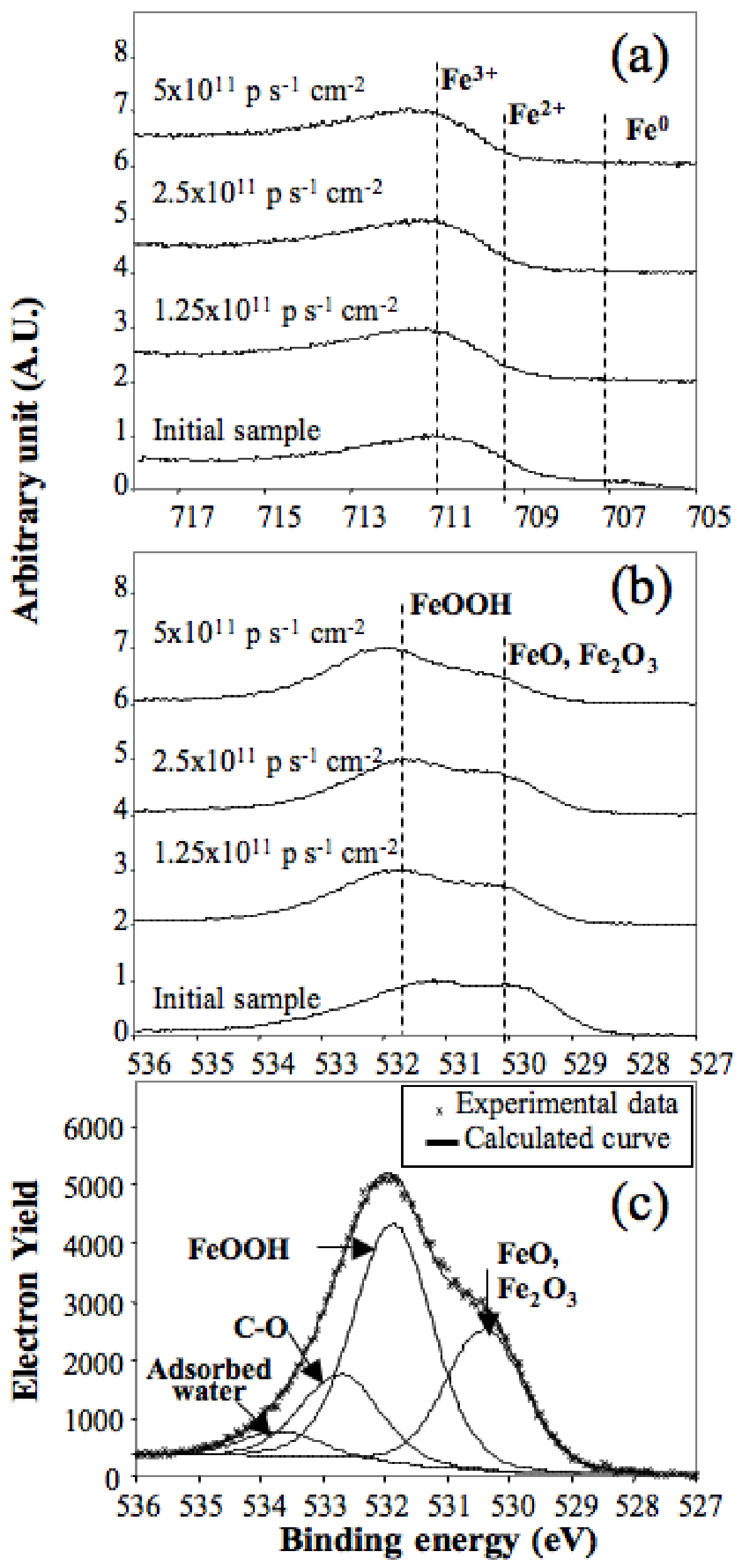




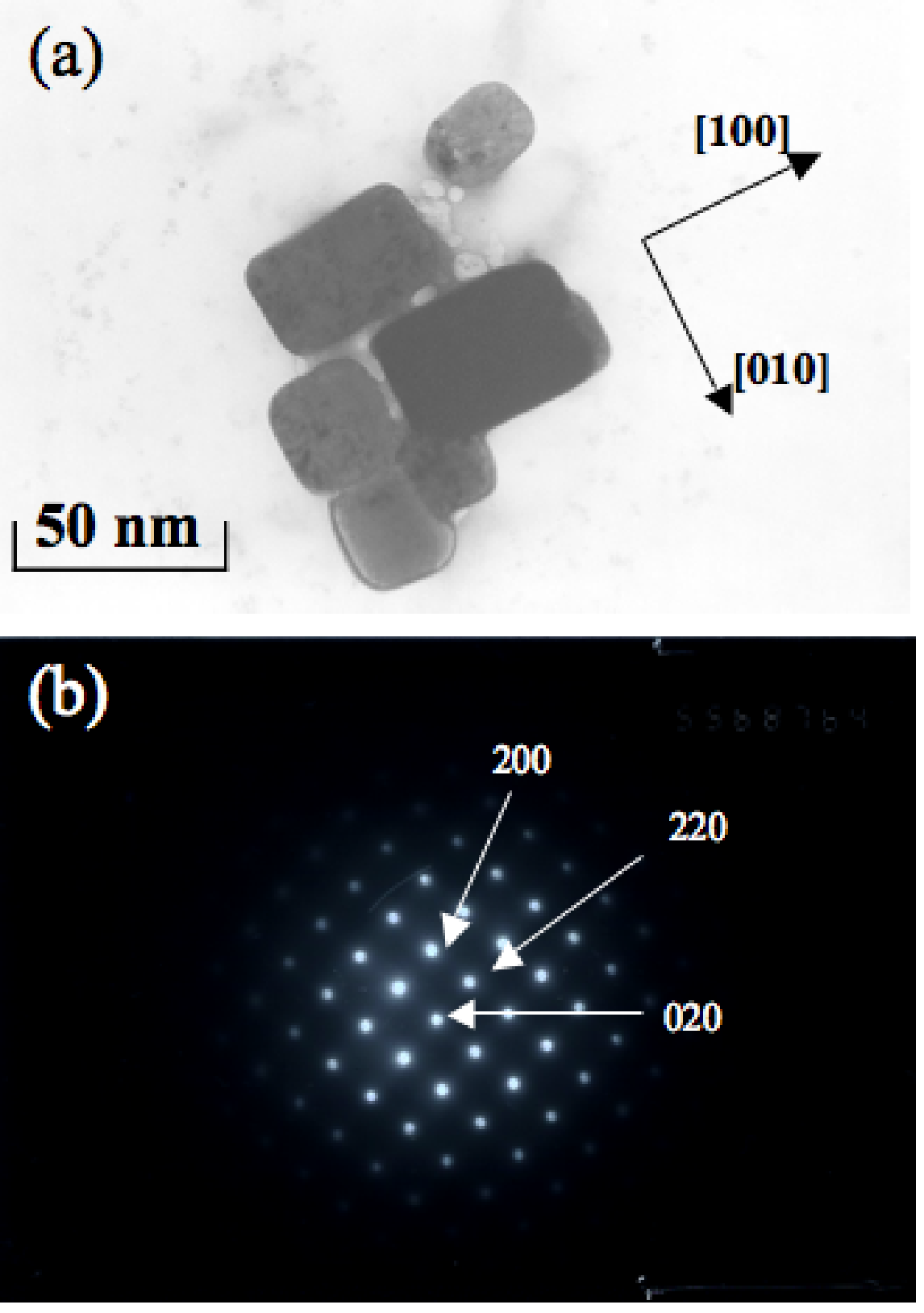




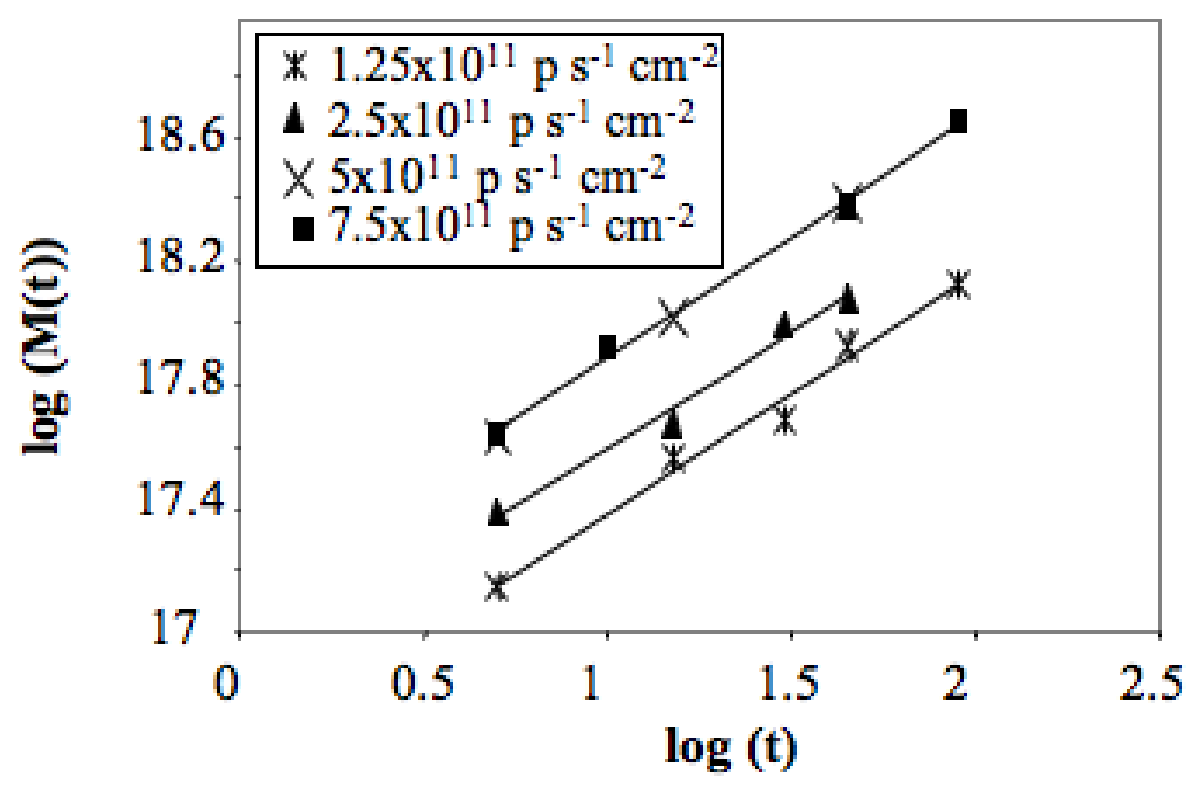




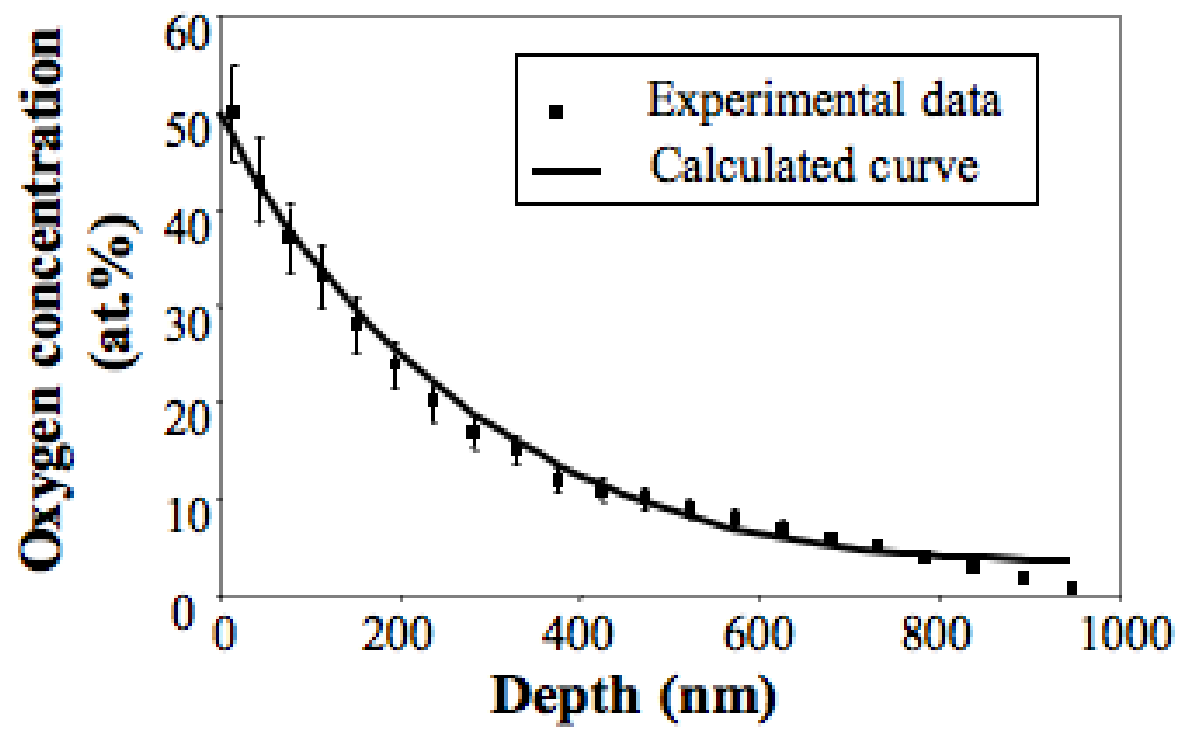




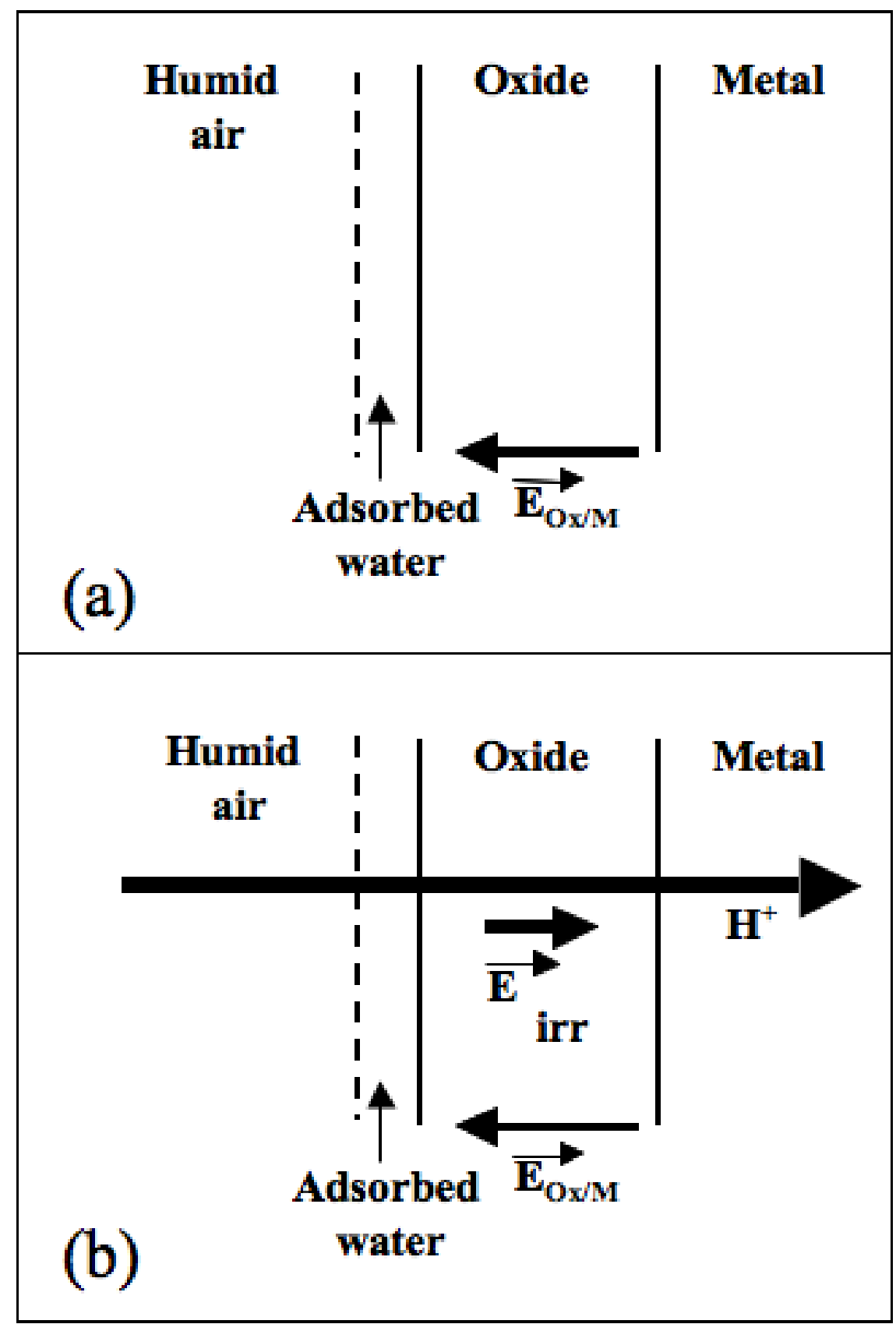




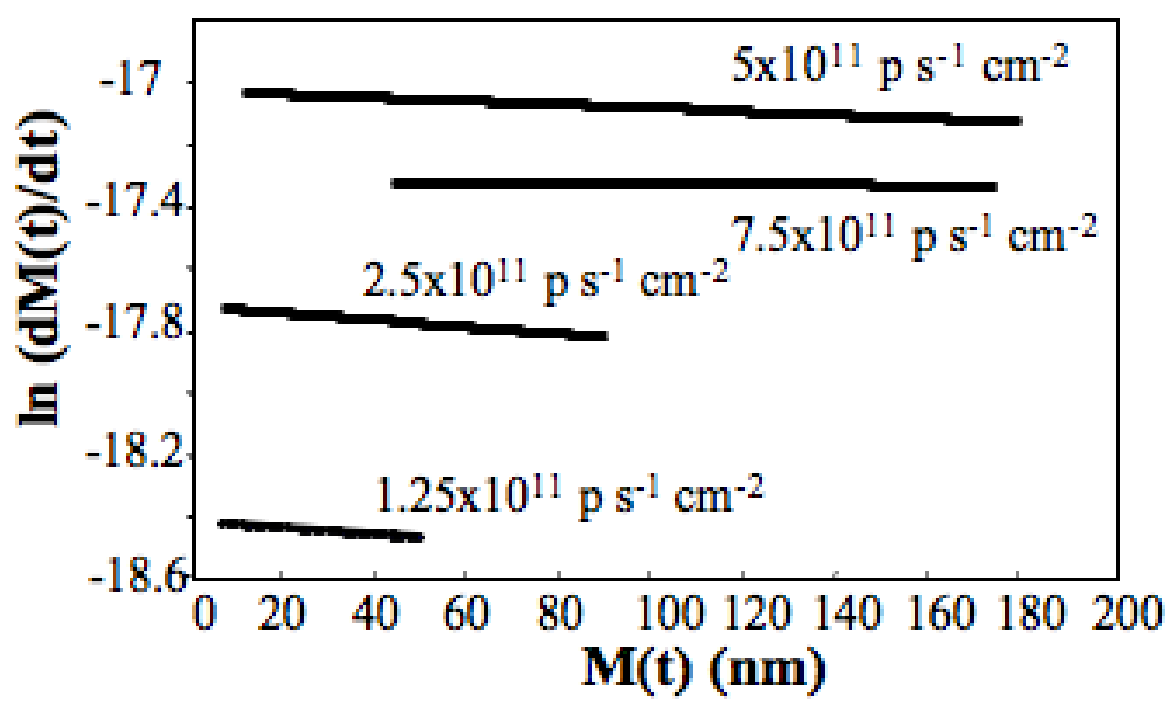

